Revista Iberoamericana. Vol. LXVI, Núm. 192, Julio-Septiembre 2000, 557-569

\title{
LA CUESTIÓN IDEOLÓGICA DEL AMERICANISMO EN EL ENSAYO HISPANOAMERICANO
}

\author{
POR \\ HÉCTOR JAIMES \\ North Carolina State University
}

\begin{abstract}
To conceive a true utopia, to sketch, with conviction, the structure of an ideal society, requires a certain dose of ingenuousness, even of stupidity, which, being too evident, ultimately exasperates the reader.
\end{abstract}

E. M. Cioran, History and Utopia

El americanismo ha marcado el origen y buena parte del desarrollo de lo que hoy llamamos literatura hispanoamericana. ${ }^{1}$ Aunque desde el período colonial aparecen visos de esta tendencia, ${ }^{2}$ es a partir de la independencia política alcanzada por Hispanoamérica en el siglo XIX, cuando surge la noción de la emancipación cultural o mental; esta noción estimuló a los intelectuales a desarrollar la temática continental principalmente en el aspecto étnico, geográfico ${ }^{3}$ e histórico. Esto es, el carácter de lo americano adquirió un valor positivo a priori y sin proponérselo, inauguró toda una línea de producción literaria que seguirían los escritores más destacados del momento. Sin embargo, esta postura ejerció una función negativa sobre las letras, ya que redujo la literatura a una representación tautológica de lo expresado; en este sentido, todas aquellas obras marcadas bajo este emblema muestran

1 Como bien apunta Arturo Andrés Roig, “desde la aparición de la América Poética de Juan María Gutiérrez, entre 1846 y 1847, hasta la publicación en nuestros días de la obra América Latina en su Literatura, patrocinada por la UNESCO (1972), hay una línea de continuidad indiscutible que muestra anudados el primitivo 'americanismo' en las letras, con el actual 'latinoamericanismo' en el mismo terreno" (El pensamiento 33).

2 Para Alberto Zum Felde, “el predominio de la temática americana en el campo ensayístico, empieza a manifestarse ya dentro del régimen del coloniaje y aun desde sus primeras décadas. Tanto como ha ocurrido después de la Independencia, mucho antes de ella los escritos que no tratan de temas americanos, que no se refieren a América misma, son los menos; tan menos son, en relación al conjunto, que casi configuran la excepción de la regla” (Índice 23). De la misma manera, según Emilio Carilla, en la época colonial hay un americanismo "oculto" o "fragmentario"; es decir, "no declarado" (Hispanoamérica 50).

3 En el Facundo (1845) de Domingo F. Sarmiento, texto programático y fundacional de la literatura del siglo XIX, encontramos un buen ejemplo que demuestra la concepción que vincula directamente a la naturaleza y la literatura. Ahí leemos: "Si un destello de literatura nacional puede brillar momentáneamente en las nuevas sociedades americanas, es el que resultará de la descripción de las grandiosas escenas naturales” (21, énfasis mío). 
un soliloquio casi imposible de superar, ya que la superación no sólo era vista como un desvío del modelo, sino como un atentado en contra de lo que se percibía estéticamente como literatura. Hoy, en pleno comienzo del siglo XXI, es hora de dar explicación al carácter ideológico de esta tendencia; en principio, el americanismo aparece con un signo estético, pero intenta al mismo tiempo cumplir una función específica: crear una conciencia cultural. Por otro lado, y en relación al tema que abordaré a continuación, es claro observar cómo desde el siglo pasado hasta la primera mitad del siglo XX, el americanismo ha sido el tema predilecto de los ensayistas.

En las obras de Simón Bolívar(1783-1830) y de Andrés Bello(1781-1865) encontramos dos antecedentes significativos de este movimiento. En la "Carta de Jamaica” (1815), Bolívar expresa la necesidad de resguardar la unidad hispanoamericana. "Nosotros", dice, "somos un pequeño género humano; poseemos un mundo aparte" (69). Se trata de un "nosotros" que intenta marcar una frontera cultural y establecer un espacio autóctono a pesar de la continuidad histórica entre América y Europa; es decir, el “nosotros” intenta crear una ruptura que genere, establezca diferencias y formalice las bases para posteriormente implementar todo un proyecto continental. De igual manera, en la "Alocución a la poesía” (1823) Andrés Bello pide que se le cante a América y no a la “culta Europa” (20). En ambos casos se puede notar que antes de ser una auténtica postura estética, innovadora y creativa, el americanismo se presenta de manera ideológica. ${ }^{4}$ Así sucede también en Dogma socialista (1846) de Esteban Echeverría. “El gran pensamiento de la revolución” — dice"no se ha realizado. Somos independientes, pero no libres. Los brazos de la España no nos oprimen; pero sus tradiciones nos abruman. De las entrañas de la anarquía nació la contrarrevolución” (193). Vemos entonces que la temática americana se asumió de una manera acrítica, ${ }^{5}$ dándose por sentado que poseía en sí un valor universal e incuestionable. De tal modo, aquellos textos que poseyeran directa o indirectamente rasgos americanistas pasaron a formar parte de una pequeña tradición y ahora los estudiamos de manera canónica; sin embargo, la verdadera emancipación cultural no debería consistir en la simple mención de “América”, sino en encontrar el universalismo artístico que, aunque tenga su base en el pasado, lo supere. Como observa el filósofo mexicano Leopoldo Zea en Dos etapas del pensamiento en Hispanoamérica: Del romanticismo al positivismo: “el pasado no es algo que se elimine así, sin más. El pasado, si no es plenamente asimilado, se hace siempre presente” (23). ${ }^{6}$

\footnotetext{
4 La carga ideológica que va a adquirir la literatura hispanoamericana durante el primer tercio del siglo XIX va a generar lo que José Luis Martínez clasifica en tres momentos: la narración costumbrista, la poesía gauchesca, y la prosa de los pensadores (“Unidad y diversidad” 74).

5 Como apunta Agustín Martínez, la imagen de América Latina que elaboró la cultura académicouniversitaria, así como el grupo del boom literario y los ensayistas consistió en un grupo de "generalizaciones conceptuales no sometidas a crítica" (132).

6 Esta idea va a marcar la obra y el pensamiento del filósofo, que casi treinta años después - y de manera similar- dirá en Dependencia y liberación en la cultura latinoamericana: "La historia, nuestra accidentada y contradictoria historia, tiene antes que ser asimilada, como ha de ser igualmente asimilada la historia de nuestros dominadores, que haber tomado conciencia de la forma como esta historia ha sido nuestra, el papel que jugamos, queramos o no, dentro de la misma, posibilitando su progreso sobre nuestra subordinación” (26).
} 
En un territorio recientemente constituido y en busca de una definición de como se encontraba Hispanoamérica durante el siglo XIX, los letrados contribuyeron en gran medida a su formación cultural, pero en vez de dejar que el continente adquiriera su propia fisonomía de manera espontánea, forzaron, ideologizaron y homogeneizaron dicha formación. Ante el intento de unificar las diferencias nacionales, pasaron por alto la existencia misma de los puntos de desencuentro entre los países de similar origen cultural; esto trajo como consecuencia que Hispanoamérica se concibiera tan sólo conceptualmente, mas no como una región viva y habitada por seres humanos concretos. Muchos ensayistas han tratado de imponer sus escritos como verdaderos esquemas de pensamiento y acción, y han pretendido borrar o crear fronteras para revelar una identidad cultural unívoca y homogénea; pero esta actitud es en realidad un gesto forzado y aunque a veces los escritos puedan imponerse momentáneamente, la realidad tiende a superar, en todos los aspectos, al texto que intenta reducirla a un esquema o a una utopía. Esta es la crítica que le podríamos formular a Bolívar al decir, en la ya citada “Carta de Jamaica”, que el Nuevo Mundo “ya tiene un origen, una lengua, unas costumbres y una religión” (81). Por el contrario, el origen, la lengua, la religión y las costumbres son múltiples y muy variadas. En este sentido, según Beatriz Pastor Bodmer: "El descubrimiento de América trajo consigo una reactivación vertiginosa de los componentes utópicos de la tradición occidental . . . El primero era el de la ciudad ideal, formulado por los griegos. El segundo el paraíso de la tradición judeocristiana” (3-4). Así, mediante el americanismo literario se intentó fundar un modelo estético que funcionara independientemente de Europa; esto es, se quiso romper con una rica tradición europea sin antes superarla. Aunque la ideología americanista repercutió sobre distintos géneros literarios, fue en el ensayo donde encontró el medio más directo para su expresión, previniendo que este género se desarrollara de manera libre y crítica, los dos rasgos principales que le corresponden.

El ensayo no contempla limitaciones temáticas o estilísticas y puede contener todos los géneros literarios sin restringirse a ninguno de ellos. Su dificultad reside en el hecho de que a través de él, el autor no se propone entretener al lector como lo hace el teatro, la poesía o la novela; por el contrario, muchas veces le presenta al lector exigencias adversas al goce literario, puesto que el género es básicamente una expresión libre del pensamiento y las ideas. Esto ha contribuido a que el ensayo se marginalizara con respecto al resto de los géneros, despertando tan sólo la atención de especialistas y lectores ávidos. Pero es precisamente la capacidad de adoptar esta ilimitada gama estilística y temática lo que constituye la riqueza de este género; sin embargo, sus múltiples posibilidades expresivas fueron opacadas, en el caso hispanoamericano, por haberse restringido casi de manera exclusiva a desarrollar temas americanistas. Más aún: fue tan vigoroso el ímpetu de insistir sobre esta tendencia que el género semeja un eco de repetitivas voces en un intento vacuo de presentar a Hispanoamérica culturalmente superior a Europa. Sin embargo, aunque el americanismo se originó principalmente como una reacción en contra de la cultura europea dominante, las obras de Martí, Rodó, y Ugarte, son tres excelentes ejemplos de americanismos en contraposición a los Estados Unidos. En efecto, el ensayo fue el vehículo de expresión más propicio para combatir la cultura dominante del momento, lo cual hizo que adquiriera un viso ideológico resaltante. 
Germán Arciniegas, uno de los ensayistas más destacados sobre el tema americanista, se pregunta en Nuestra América es un ensayo: “¿Por qué la predilección por el ensayo — como género literario- en nuestra América?”, y luego responde: “La razón de esta singularidad es obvia. América surge en el mundo, con su geografía y sus hombres, como un problema. Es una novedad insospechada que rompe con las ideas tradicionales. América es ya, en sí, un problema, un ensayo de nuevo mundo, algo que tienta, provoca, desafía a la inteligencia” (5, énfasis mío). Aquí el escritor colombiano reconoce que el ensayo es la mejor vía para discutir y resolver la problematicidad de la cuestión americana ya que América misma es un "ensayo". Esto es, usa el género literario que mejor se adapta a la problematicidad del asunto que trata; por lo tanto, la palabra “ensayo" debe ser entendida a través de su doble significación: como aproximación e intento, y como escritura. En este sentido, en Hispanoamérica se ensayó toda una tradición cultural europea que definitivamente contribuyó a dar forma y sentido al continente; pero de la misma manera, los intelectuales hispanoamericanos ayudaron a dicha formación a través de su escritura. Así, América puede también ser entendida como el "ensayo” de los ensayistas.

El surgimiento del ensayo americanista en el siglo pasado podría ser justificado desde el punto de vista histórico, ya que se trataba de un momento en el cual la preservación de la identidad continental precedía (o se oponía) a la libertad artística. En relación con Europa, el americanismo puede interpretarse como la etapa narcisista de la literatura hispanoamericana: aparece como una especie de rebeldía contra el padre y sin verdaderamente haber logrado la independencia estética de la que hace alarde. El narcisista se piensa como único, diferente y universal antes de darse cuenta de que su ser se halla en un constante diálogo con el otro. Se cree el centro del mundo y toda expresión de sí mismo debe verse como un denodado gesto de rebeldía, mas no como una representación libre y madura de su ser. La unidad expresada por el americanismo muestra más bien la desunión ${ }^{7}$ y la debilidad de Hispanoamérica, ya que ante una sólida y verdadera unión serían innecesarias y hasta redundantes todas las posturas que aboguen por ella. Ésta debe ser vista entonces como una perspectiva romántica; en palabras de José Luis Martínez: “emancipación y romanticismo eran, en efecto, corrientes paralelas y parecían alimentarse mutuamente” (“Unidad y diversidad" 94). Pero el americanismo que invoca la unidad hispanoamericana muestra primero que todo una actitud política ante el pensamiento y la literatura. "Tenemos la obligación”, dice Manuel Ugarte, “de mantener el patriotismo geográfico, étnico, cultural, que nos deparó la historia” (238). Por otro lado, por ser el género literario que mejor expresa la discusión de las ideas, el ensayo se vio forzado a constituir el medio de la pugna política y cultural que emergió a raíz de la independencia de las naciones hispanoamericanas. Esta ideología pasó por alto la interdependencia continental, las diferencias nacionales y la posibilidad misma de la disparidad espiritual; de esta manera, el lema de la unidad hispanoamericana debe verse tan sólo como la aspiración truncada de Bolívar y no como la base real sobre la cual se pudiera fundar una estética. En este sentido, resulta alarmente notar el vacío crítico que existe con respecto al rumbo que tomó el ensayo debido al

7 Esta desunión la caracteriza Ugarte de la siguiente manera: “Contemplemos el mapa de América. Lo que primero salta a los ojos es el contraste entre la unidad de los anglosajones ... y el desmigajamiento de los latinos” (17). 
americanismo. La crítica literaria contemporánea tan sólo se ha conformado con elaborar historias, ${ }^{8}$ antologías, ${ }^{9}$ o estudios independientes de autor, sin verdaderamente explicar o inclusive plantear el problema. En In Quest of Identity: Patterns in the Spanish American Essay of Ideas, 1980-1960 (1967), Martin S. Stabb hace un detallado análisis de las formas que sigue el ensayo hispanoamericano, pero en lo que respecta al americanismo, se realiza más bien una historia o un recuento de los máximos exponentes y no una verdadera crítica de los principios y efectos que esta tendencia crea. Asimismo, en Del ensayo americano (1945), el primer texto propiamente de crítica sobre el ensayo, Medardo Vitier se limita a señalar que "muy considerable es la función del ensayo como tipo de prosa en que se exponen y discuten las cuestiones vitales latinoamericanas" (7); y luego dice: "el ensayo aviva, sobre todo de unos cincuenta años acá, las mejores savias del americanismo” (8). Sin embargo, no se exponen ni se analizan con profundidad las razones que hicieron posible el americanismo, ni el impacto — negativo— sobre la literatura continental.

En el Ariel (1900) de José Enrique Rodó, el primer gran ensayo hispanoamericano del siglo XX, encontramos signos vitales del americanismo. La obra de Rodó, esencialmente didáctica, se caracteriza por ver en Hispanoamérica la posibilidad de crear un proyecto continental. En voz del maestro Próspero, Rodó se dirige a la juventud bajo la estatua de Ariel y dice: “América necesita grandemente de su juventud. —-He ahí por qué os hablo. He ahí por qué me interesa extraordinariamente la orientación moral de vuestro espíritu. La energía de nuestra palabra y vuestro ejemplo puede llegar hasta incorporar las fuerzas vivas del pasado a la obra del futuro” (10). De la misma manera, en Motivos de Proteo (1909), expone su más ambicioso proyecto didáctico sobre la personalidad del individuo. Según el maestro uruguayo, el individuo debe conocerse a sí mismo para así descubrir la auténtica vocación interior que se encuentra en forma latente en lo más profundo de cada ser humano. Rodó no concibe al individuo como un ser estático e inmutable; en principio, para que el hombre sea verdaderamente libre, deberá reformarse interiormente y tomar conciencia de que la ley del cambio es la ley que gobierna al universo y que coloca al individuo constantemente en la esfera de la contradicción: "mientras dura la vida, en un solo arrebatado impulso, tienen fuerza con que prevalecer sobre lo complejo de nuestra naturaleza hasta el punto de anular la diversidad, la inconsecuencia y la contradicción, que se entrelazan con las mismas raíces de nuestro ser” (Motivos 93). Si Ariel se centra más en la cuestión americanista, Motivos de Proteo hace hincapié en el descubrimiento espiritual; sin embargo, Motivos tiene un trasfondo histórico importante que resalta al mismo tiempo su fe en el continente: “¿Hay cosa que te interese más que descubrir lo que está en ti y en ninguna parte sino en ti: tierra que para ti sólo fue creada; América cuyo único descubridor posible eres tú mismo, sin que puedas temer, en tu designio gigante, ni émulos que te disputen la gloria, ni conquistadores que te usurpen el provecho?” (Motivos 84).

El didactismo que encontramos en Ariel va más allá de una simple polémica Norte-Sur, ya que tiene una intención ideológica fundamental: advertirle al lector los peligros del

\footnotetext{
8 Véanse los trabajos de Crawford, Earle y Mead, Fernández, Oviedo, Sanjuan, Stabb, Zum Felde citados en la bibliografía.

9 Entre las más importantes pueden destacarse: Carlos D. Hamilton, El ensayo hispanoamericano; José Luis Martínez, El ensayo mexicano; Susana Rotker, Ensayistas de nuestra América y John Skirius, El ensayo hispanoamericano del siglo XX.
} 
utilitarismo norteamericano. Rodó ve este utilitarismo como un detrimento de la espiritualidad hispanoamericana, ya que Hispanoamérica ha tendido a imitar a los Estados Unidos. Así, "la civilización de un pueblo adquiere su carácter, no de las manifestaciones de su prosperidad o de su grandeza material, sino de las superiores maneras de pensar y de sentir que dentro de ella son posibles” (Ariel 25). La espiritualidad y el pensamiento son puestos por encima de la riqueza material, pero Rodó no esgrime los lineamientos de este pensamiento sino que se basa simplemente en el carácter positivo del ser americano. Por eso dice: "No veo la gloria, ni en el propósito de desnaturalizar el carácter de los pueblos, su genio personal, para imponerles la identificación de un modelo extraño al que ellos sacrifiquen la originalidad irreemplazable de su espíritu; ni en la creencia ingenua de que eso pueda obtenerse alguna vez por procedimientos artificiales e improvisados de imitación" (Ariel 34). La frontera que marca Rodó es ciertamente una frontera cultural, la cual tiene como objetivo preservar y dejar que se desarrolle el germen de lo que está aún por desarrollarse. En este sentido, el espíritu y pensamiento hispanoamericanos son concebidos como proyectos a realizarse en el futuro donde el ensayista interviene para destacar la misión espiritual y étnica que Hispanoamérica debe llevar a cabo:

\begin{abstract}
tenemos — los americanos latinos — una herencia de raza, una gran tradición étnica que mantener, un vínculo sagrado que nos une a inmortales páginas de la historia, confiando a nuestro honor su continuación en lo futuro. El cosmopolitismo, que hemos de acatar como una irresistible necesidad de nuestra formación, no excluye, ni ese sentimiento de fidelidad a lo pasado, ni la fuerza directriz y plasmante con que debe el genio de la raza imponerse en la refundición de los elementos que constituirán al americano definitivo del futuro. (Ariel 35, énfasis mío)
\end{abstract}

El nosotros de Rodó, como el de Bolívar, intenta constituir una unidad subjetiva uniforme; se presenta ideológicamente de acuerdo consigo mismo. También intenta crear desde el punto de vista objetivo una unidad homogénea que comprenda a todas las naciones hispanoamericanas. Este recurso supone, como nos dice Arturo Andrés Roig en Teoría y crítica del pensamiento latinoamericano, una definición del hombre latinoamericano por afirmación, y sus desarrollos más amplios tienen su origen histórico en aquellas ideologías a las que podríamos denominar en general como "americanista", dentro de las cuales se destacan el "bolivarismo", el "latinoamericanismo" más tarde, y en general las formas del "hispanoamericanismo", todas las cuales se extienden desde los albores del siglo XIX y cobran fuerza, en particular la última de las citadas, alrededor del 1900 (44). ${ }^{10}$

Ahora bien, la ideología que se expresa a través del nosotros o de lo nuestro no se originó con Rodó ya que es previa a Ariel. Recuérdese que uno de los ensayos más emblemáticos de José Martí se titula "Nuestra América” (1891); posteriormente Pedro Henríquez Ureña, consciente de esta noción de pertenencia, tituló a uno de sus libros Seis

${ }^{10}$ Es importante destacar que el problema de la definición ya lo había planteado Alberto Zum Felde en El problema de la cultura americana al afirmar que: "Pueblos sin genio propio, definido, como lo de esta América Latina, no pueden dar sino hombres de rasgos espirituales indefinidos y sin propiedad. Tal es el drama del hombre sudamericano de nuestro tiempo, que por desdoblamiento intelectual se convierte en problema; y tal el problema, que por angustia intelectual, se transforma en drama de conciencia” (11). 
ensayos en busca de nuestra expresión (1928). De la misma manera, la formación del sujeto histórico en la obra del venezolano Mariano Picón-Salas cobra mayor sentido cuando se lee a la luz del pronombre nosotros. Las obras tempranas de este ensayista son de corte autobiográfico, Buscando el camino... (1920) y Mundo imaginario (1927); en ellas persiste una actitud narcisista expresada a través del yo. Por el contrario, sus obras posteriores suprimen el uso del yo y asumen una posición global y totalizadora expresada a través del nosotros, como lo demuestran De la conquista a la independencia: Tres siglos de historia cultural hispanoamericana (1944) y Regreso de tres mundos: un hombre en su generación (1959). Igualmente, en las primeras páginas de Indología de José Vasconcelos el programa de representación cultural se presenta a partir de la noción de lo nuestro: "Hablo de caracterizar nuestra existencia colectiva iberoamericana [...] nuestro propósito debe ser representarnos, precisar los rasgos formativos de un organismo que apenas lleva un poco más de cien años de vida autóctona” (1, énfasis mío). Sin embargo, a diferencia de otros ensayistas, Vasconcelos reconoce que la representación cultural que se propone llevar a cabo es compleja ya que amerita comprender y conocer la totalidad americana; es decir, la heterogeneidad se le presenta como un problema, por eso propone el término “indología”, a través del cual estudiará la totalidad y universalidad del continente. No obstante, de manera similar, el ensayista se repliega en el nosotros a la hora de caracterizar esta totalidad:

\begin{abstract}
La conciencia de nuestra unidad debe ser el primer factor de nuestra acción; somos un agente aparte. El Norte y el Sur son, en nuestro continente, no diré yo que dos mundos contrarios, dos East y West que nunca llegarán a entenderse, según reza la frase conocida de Kipling. Nosotros, al contrario, procedemos del tronco común de la civilización cristiana, cuya base es la igualdad y la hermandad de todas las estirpes, y tenemos además la infinidad de conveniencias y de simpatías recíprocas que fatalmente nos obligan a estar juntos en la obra común del progreso humano. (Indología 12, énfasis mío)
\end{abstract}

Pero el nosotros encubre toda una estratagema discursiva e ideológica que es necesario esclarecer. El nosotros denota un grupo y una totalidad que separa y unifica al hablante; más aún, le da un carácter homogéneo y verosímil ya que se muestra como el acuerdo entre varias conciencias. Sin embargo, el nosotros de los ensayistas no incorpora a ningún grupo en particular sino la voz del escritor mismo; es decir, el nosotros sirve de camuflage del yo y de la individualidad del autor. Se trata en realidad de un yo que no quiere mostrarse como tal puesto que develaría su imposición arbitraria y unilateral; el nosotros entonces sirve para amortiguar el peso de esta imposición y darle más credibilidad al discurso. Asimismo, esta actitud de los ensayistas va en contra de uno de los rasgos principales del género, ya que como dice José Luis Martínez, el ensayo es “ante todo, una peculiar forma de comunicación cordial de ideas en la cual éstas abandonan toda pretensión de impersonalidad e imparcialidad para adoptar resueltamente las ventajas y las limitaciones de su personalidad y parcialidad. En los ensayos más puros y característicos cualquier tema o asunto se convierte en problema íntimo, individual ... y se presenta como testimonio, como voto personal y provisional” (El ensayo 10). ${ }^{11}$ Igual sucede con el adjetivo posesivo nuestro, el cual le da fuerza al discurso

11 Del mismo modo, Graham Good señala que "the discourse of the essay is uniquely personal and thus non-disciplinary" (6). 
en tanto que denota una pertenencia, un lugar en el tiempo y en el espacio. Pero de manera similar, se trata de una pertenencia ficticia y vacía, que es usada además de manera inapropiada porque el autor se ha conferido a sí mismo los atributos de un vocero histórico; en fin, detrás del nosotros y de lo nuestro no existe sino la presencia escuálida de un autor que quiere asumir las riendas de una representación cultural y que ejerce un poder maravilloso a través de su escritura. Como bien ha señalado Ángel Rama, los letrados hispanoamericanos "fueron los únicos ejercitantes de la letra en un medio desguarnecido de letras, los dueños de la escritura en una sociedad analfabeta y porque coherentemente procedieron a sacralizarla dentro de la tendencia gramatológica constituyente de la cultura europea” (La ciudad 33).

El americanismo también encierra un utopismo estético que le confiere valor sólo a aquellos textos que muestren una preocupación por el continente. En el Índice crítico de la literatura hispanoamericana: Los ensayistas (1954), Alberto Zum Felde señala que la característica principal del ensayo hispanoamericano, desde los orígenes coloniales hasta el presente, "es la que se refiere al predominio de la temática nacional o continental, en su conjunto”. De igual manera, señala que son numerosos los ensayistas (Bello, Sarmiento, Alberdi, Lastarria, Echeverría, Acosta, Hostos, Martí, González Prada, Rodó, Mariátegui, Arguedas, Henríquez Ureña, Vasconcelos, Martínez Estrada) que han mostrado de una manera u otra, esta preocupación (Índice 7). ${ }^{12}$ Esto es, han querido comprender, interpretar y reescribir la Historia del continente, pero esto ha forzado que la percepción de Hispanoamérica tome lugar a partir de una generalidad: como un todo. ¿Qué sucedería entonces con aquellos escritores que toman distancia de esta postura; o inclusive, con aquellos que la critican? Habría que recordar la manera tan despectiva con la que Rodó se refiere al poeta nicaragüense Rubén Darío al decir que no es el poeta de América; afirmación que se hace precisamente en el momento álgido del modernismo; el período en el cual algunos escritores hispanoamericanos comienzan a separarse de la temática americana y se proponen experimentar más libremente y sin ataduras ideológicas. Aunque la caracterización de Rodó fue hecha en relación a un poeta y no a un ensayista, resulta obvio que los ensayistas con tendencias no americanistas también habrían sido caracterizados de la misma manera. No obstante, es precisamente Rubén Darío quien en Historia de mis libros deja al descubierto la problemática estética creada por el americanismo:

Asqueado y espantado de la vida social y política en que mantuviera a mi país original un lamentable estado de civilización embrionaria ... tendí hacia el pasado, a las antiguas mitologías y a las espléndidas historias ... pues no se tenía en toda la América española como fin y objeto poético más que la celebración de las glorias criollas, los hechos de la independencia y la naturaleza americana; un eterno canto a Junín, una inacabable oda a 'La agricultura de la zona tórrida', y décimas patrióticas. (60-61)

12 Bajo esta perspectiva, para Eugenia Revueltas, "la reflexión ensayística, tanto en el siglo XVIII y a finales del siglo XIX con la generación del 98 como con la generación de ensayistas hispanoamericanos de finales del siglo XIX y XX, está permeada eminentemente por un propósito ético, político y social ....” (103); y para Pilar Concejo, "el ensayo en Latinoamérica ha sido, pues, y sigue siendo, la voz de la conciencia del hombre sensible ante su historia” (633). 
Sin embargo, la obra de Darío tomó un rumbo diferente a partir de la crítica del maestro uruguayo. En el prefacio de Cantos de vida y esperanza leemos: "Yo no soy poeta para muchedumbres. Pero sé que indefectiblemente tengo que ir a ellas” (109). Esta conciencia del público será una especie de antídoto al ser de su poesía “mía, en mí” que define en las "Palabras liminares" de Prosas profanas, y que servirá de respuesta a la crítica de Rodó. No obstante, la actitud de Rodó es ambivalente ya que por un lado critica el esteticismo de Darío, y en general el de todo el movimiento, pero por otro, se declara a sí mismo modernista. El modernismo y el americanismo distan de lo que se había intentado mediante la llamada emancipación cultural; por el contrario, ambas tendencias muestran que no superaron al europeísmo que las precede. Esto es, el modernismo, considerado el primer gran movimiento cultural auténticamente hispanoamericano, no podría entenderse fuera de la esfera europea, bien sea a manera de diálogo — como sucede con la mayoría de los modernistas— o de rechazo como en el caso de Rodó.

En la segunda mitad del siglo XX se puede notar con claridad la decadencia del americanismo literario. Si durante el siglo XIX se escribieron ensayos que contribuyeron a revalorar el pasado americano, así como a redefinir la identidad nacional y continental, en la segunda mitad de este siglo surge una conciencia más crítica ante la herencia cultural de la que se hacía alarde anteriormente. En el primer libro del mexicano Edmundo O’Gorman, Fundamentos de la Historia de América (1942), se percibe un signo crítico determinante que podríamos considerar como un punto de partida que rompe con la tradición interpretativa acrítica sobre Hispanoamérica. El ensayista cuestiona las premisas históricas del continente y señala que “casi la totalidad de la elaboración histórica ha sido llevada a cabo con notoria unilateralidad, como si los hechos de la vida americana fuesen algo independiente de la vida europea” (viii). Igualmente, en Crisis y porvenir de la ciencia histórica (1947), hace un replanteo de la cuestión filosófica que subyace en torno al descubrimiento, ya que para indagar acerca de “qué es” en sí el descubrimiento es necesario conocer la fundamentación filosófica previa (Crisis X). O’Gorman reinterpreta el postulado básico del descubrimiento (Colón descubrió América) y critica a aquellos que han tomado esta premisa de manera absolutamente cierta. "No parecen comprender", dice, "que en lugar de adicionar o rectificar la vieja noción, hay que empezar por desfundarla, exhibiendo sus bases y presupuestos” (Crisis 8). En Crisis también se hace una fuerte crítica a la metodología de la historiografía tradicional que estudia los eventos históricos bajo patrones tomados de las ciencias naturales, en tanto despoja al evento de la red de asociaciones en la cual se encuentra circunscrito. Cosificar al hecho histórico y despojarlo de esta red de asociaciones, muestra que la historiografía tradicional examina los eventos de manera abstracta y olvida que todo evento, por más remoto que sea, tiene un significado específico que hay que aclarar para el Hombre contemporáneo. Como dice O’Gorman, la historiografía tradicional no intenta comprender lo humano del pasado, sino explicar lo pasado humano (Crisis 79). Ahora bien, ¿no es cierto que una crítica al americanismo debe comenzar precisamente por una crítica y comprensión de la formación histórica del continente americano?

Esta sugerencia es lo que se desprende de la obra de O'Gorman, ya que la Historia no es vista como algo fijo, sino como algo que es susceptible a cambios; principalmente a partir de la reinterpretación. Por ejemplo, la normativa de los fundamentos historiográficos estudiados en su libro La idea del descubrimiento de América (1951) desmiente los 
planteamientos historiográficos anteriores, en tanto que el ensayista no pretendió escribir una Historia sino discutir los principios histórico-teóricos del descubrimiento. Tras el análisis de estos postulados descubre una crisis historiográfica que podríamos emparentar con una crisis de representación cultural. Esto es, los hechos no están separados de la forma cómo están representados; su representación es significativa por cuanto le presenta al lector una realidad dada, concreta. Así, O’Gorman busca redefinir la historiografía y la comprensión histórica del ser americano. La Historia, dice:

\begin{abstract}
es un proceso temporal susceptible de variaciones entitativas que se actualizan en modos de ser históricamente diferenciados, ni más auténtico uno que otro ni más o menos adelantado o atrasado el uno respecto al otro. No es, pues, ni un proceso teleológico entitativamente homogéneo ni un proceso esencialista entitativamente heterogéneo; es un proceso dinámico temporal entitativamente mutante. (México 113)
\end{abstract}

Vemos entonces que la Historia, entendida como movimiento humano en el tiempo, es un hacerse y deshacerse, así como una continua creación de eventos. La Historia, no es una entidad fuera de la participación humana; tampoco le es extraña al individuo, puesto que existe mediante su actividad cotidiana. Se trata, en fin, de un universalismo al que hay que despertar ya que aceptarlo es la "circunstancia histórica fundamental de nuestro tiempo" (México 117). O’Gorman va más allá de la mitificación de la Historia y muestra que los hechos ocurridos no pueden ser tratados como piezas arquelógicas, sino que deben ser reinterpretados para así darle un sentido más omniabarcador.

El laberinto de la soledad (1950) de Octavio Paz y Del buen salvaje al buen revolucionario (1976) de Carlos Rangel, son dos libros que siguen esta línea desmitificadora del pasado americano, y pueden considerarse como críticas al americanismo literario. En El laberinto Paz no ve la Historia de México como el acontecer humano a través de saltos dialécticos, o bajo una función determinista y predecible de los hechos; es decir, no le da a la Historia o al rasgo americanista del mexicano una validez a priori. Desde su punto de vista, el mexicano a lo largo de su Historia ha intentado reconciliarse con un origen mítico que, antes de estar ausente, determina y aparece en su realidad. No se trata de negar la Conquista o la Independencia, sino de ir más allá de la Historia (verificable) para reconocer y encontrar el pasado mítico. En este sentido, la Historia no está por encima del mito, sino en un diálogo permanente con él. Pero la característica que eleva el texto de Paz por sobre los ensayos de crítica histórica no es sólo que se enfrenta a las ideologías del determinismo histórico y al americanismo mismo, sino que lo hace manteniendo en todo momento una constante tensión estética. Esto es, la estética literaria no se ve socavada por el discurso crítico; sin embargo, no deja de ser directo y efectivo.

No sucede así con el ensayo de Rangel, cuyo tono crítico-analítico está por encima del carácter literario mismo del texto. No obstante, Del buen salvaje al buen revolucionario es el primer libro que intenta desmitificar la noción de Hispanoamérica como tierra de gracia; más bien la categoriza como tierra de "fracaso". Rangel, apoyándose en las ciencias sociales, se ocupa de explicar la circunstancia histórica de la región y con este análisis, se separa de toda un tradición de escritores que veían las bondades americanas de manera $a$ priori. De la misma manera, para Rangel los mitos europeos, así como las utopías que 
comentábamos anteriormente, provienen de Europa: "los mitos fundamentales de América”, dice, "no son en absoluto americanos. Son mitos creados por la imaginación europea, o que vienen de más lejos aún, de la antigüedad judeo-helénica y asíatica, y van a ser reformulados por los europeos maravillados de haber descubierto un 'Nuevo Mundo'” (31). Entonces, lo que hace el escritor venezolano es, por un lado, reconocer que los conceptos que determinan y caracterizan a Latinoamérica están fundamentados no sobre hechos reales y objetivos, sino sobre "mitos”. En este sentido, su ensayo le da la espalda a todas aquellas posturas que ideológicamente contribuyeron a darle un valor estético, histórico y político a Hispanoamérica de manera injustificada. Al mismo tiempo, Rangel no intenta restarle validez a los rasgos característicos glorificados por el americanismo, sino que por el contrario, intenta darle un valor menos ideológico y más objetivo.

El largo grupo de ensayistas que se aparta de la tendencia americanista ha sido ya estudiado por Martin S. Stabb en su libro The dissenting voice: The New Essay of Spanish America, 1960-1985. Sin embargo, con el comentario de la obra de O’Gorman he querido mostrar que el punto de partida de esta ruptura estético-discursiva comienza mucho antes de 1960; asimismo, la publicación de El laberinto de la soledad en 1950 marca también el momento clave de esta ruptura tanto desde el punto de vista temporal — la mitad del siglo_ como desde el punto de vista estético. Para Stabb,

one of the most fascinating aspects of the "new essay" may be seen in certain practices based on attitudes regarding the autonomy of language, the self-referential nature of the text, and even the notion of the book as artifact, as an entity possessing a kind of life ot its own beyond, or in addition to, its semiotic function. (Dissenting 96)

Pero tal vez el término "new essay” no sea el más apropiado para caracterizar la distancia estética que separa a los ensayistas de hoy con los de ayer, aunque la simple aparición de esta ruptura y su respectiva mención por parte de la crítica nos incita a pensar que lo que contiene este "nuevo ensayo" es en realidad una libertad estética primordial que demuestra una conciencia madura y crítica ante la creación artística. Se trata al mismo tiempo de una libertad estética que arriva tardíamente si la comparamos con otras literaturas a nivel mundial, pero cuya presencia en el continente era casi inevitable. Esto es, la libertad estética que emerge del llamado "nuevo ensayo" apunta hacia una trascendencia artística jamás presenciada en Hispanoamérica anteriormente, y sólo en tanto reconozcamos esta ruptura con el pasado (literario e histórico) podremos hablar de “emancipación cultural”.

BibliografíA

Arciniegas, Germán. Nuestra América es un ensayo. México: UNAM, 1979.

Bello, Andrés. Obra literaria. Caracas: Biblioteca Ayacucho, 1979.

Bolívar, Simón. Escritos políticos. Madrid: Alianza Editorial, 1990.

Carilla, Emilio. Hispanoamérica y su expresión literaria: Caminos de americanismo. Buenos Aires: Editorial Universitaria de Buenos Aires, 1969.

Concejo, Pilar. "Localismo y universalidad en el ensayo hispanoamericano”. Cuadernos hispanoamericanos 387 (1982): 631-38. 
Crawford, William R. A Century of Latin-American Thought. Cambridge, MA: Harvard University Press, 1944.

Darío, Rubén. Historia de mis libros. Managua: Editorial Nueva Nicaragua, 1988. Prosas profanas. Managua: Ediciones Distribuidora Cultural, 1984.

Earle, Peter y Robert Mead. Historia del ensayo hispanoamericano. México: Ediciones de Andrea, 1973.

Echeverría, Esteban. Dogma Socialista. La Plata: Universidad Nacional de La Plata, 1940.

Fernández, Teodosio. Los géneros ensayísticos hispanoamericanos. Madrid: Taurus, 1990.

Good, Graham. The Observing Self: A Study of the Essay. Londres: Routledge, 1988.

Hamilton, Carlos D. El ensayo hispanoamericano. Madrid: Ediciones Iberoamericanas, 1972.

Martínez, Agustín. Figuras: la modernización intelectual de América Latina: 1850-1930. Caracas: Fondo Editorial Trópykos, 1995.

Martínez, José Luis. El ensayo mexicano moderno. México: Fondo de Cultura Económica, 1971.

"Unidad y diversidad”. América Latina en su literatura. México: Siglo XXI Editores, 1990. 73-92.

O’Gorman, Edmundo. México: el trauma de su historia. México: UNAM, 1977. La idea del descubrimiento de América, historia de esa representación y crítica de sus fundamentos. México: Centro de Estudios Filosóficos, 1951. Crisis y porvenir de la ciencia histórica. México: Imprenta Universitaria, 1947. Fundamentos de la Historia de América. México: Imprenta Universitaria, 1942.

Oviedo, José Miguel. Breve historia del ensayo hispanoamericano. Madrid: Alianza, 1990.

Pastor Bodmer, Beatriz. El jardín y el peregrino: ensayos sobre el pensamiento utópico latinoamericano 1492-1695. Atlanta, GA: Rodopi, 1996.

Paz, Octavio. El laberinto de la soledad. México: Fondo de Cultura Económica, 1973.

Picón Salas, Mariano. Europa, América: preguntas a la esfinge de la cultura y otros ensayos. Selección de Guillermo Sucre. Caracas: Monte Ávila, 1996.

Regreso de tres mundos; un hombre en su generación. México: Fondo de Cultura Económica, 1959.

De la Conquista a la Independencia: tres siglos de historia cultural hispanoamericana. México: Fondo de Cultura Económica, 1950.

Rama, Ángel. La ciudad letrada. Hanover: Ediciones del Norte, 1984.

Rangel, Carlos. Del buen salvaje al buen revolucionario. Caracas: Monte Ávila Latinoamericana, 1992.

Revueltas, Eugenia. "El ensayo como forma de acercamiento y develamiento de la realidad”. Cuadernos americanos 6/48 (1994): 103-09.

Rodó, José Enrique. Ariel. Motivos de Proteo. Caracas: Biblioteca Ayacucho, 1985.

Roig, Arturo Andrés. El pensamiento latinoamericano y su aventura (I). Buenos Aires: Centro Editor de América Latina, 1994.

Teoría y crítica del pensamiento latinoamericano. México: Fondo de Cultura Económica, 1981. 
Rotker, Susana (Ed.). Ensayistas de nuestra América. 2 Vol. Buenos Aires: Editorial Losada, 1994.

Sanjuan, Pilar A. El ensayo hispánico: Estudio y antología. Madrid: Gredos, 1954.

Sarmiento, Domingo F. Facundo: Civilización y barbarie. Vida de Juan Facundo Quiroga. México: Editorial Porrúa, 1989.

Skirius, John. El ensayo hispanoamericano del siglo XX. México: Fondo de Cultura Económica, 1994.

Stabb, Martin S. In Quest of Identity: Patterns in the Spanish American Essay of Ideas, 1890-1960. Chapel Hill, NC: The University of North Carolina Press, 1967.

The Dissenting Voice: The New Essay of Spanish America, 1960-1985. Austin: University of Texas Press, 1994.

Ugarte, Manuel. La nación latinoamericana. Caracas: Biblioteca Ayacucho, 1978.

Vasconcelos, José. Indología: Una interpretación de la cultura latinoamericana. París: Agencia Mundial de Librería, s.n.

Vitier, Medardo. Del ensayo americano. México: Fondo de Cultura Económica, 1945.

Zea, Leopoldo. Dos etapas del pensamiento en Hispanoamérica: Del romanticismo al positivismo. México: El Colegio de México, 1949.

Dependencia y liberación en la cultura latinoamericana. México: Editorial Joaquín Mortiz, 1974.

Zum Felde, Alberto. El problema de la cultura americana. Buenos Aires: Editorial Losada, 1943.

Índice crítico de la literatura hispanoamericana: los ensayistas. México: Editorial Guarania, 1954. 